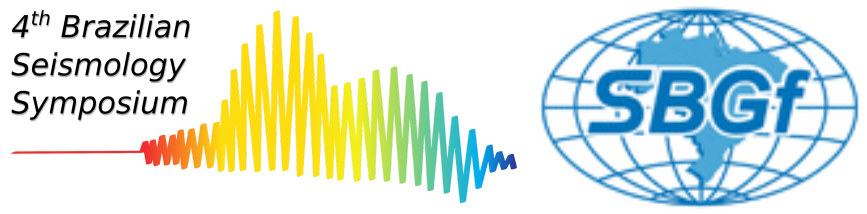

\title{
New horizons in Brazilian Seismology: expanding seismic monitoring to offshore South East Brazil
}

Diogo Luiz de Oliveira Coelho*12, Sergio Luiz Fontes ${ }^{1}$, Antonio Henrique da Fontoura Klein ${ }^{2}$, Fábio Luiz Dias ${ }^{1}$, Ítalo Cley Borges de Santana Maurício ${ }^{1}$, Arthur Antônio Machado ${ }^{3}$, Michel Franco Volpato Prado², Antônia Pamela Yhaohannah de Lima², Alexandre Augusto Cardoso da Silva $^{4}$, Carlos Eduardo Theodoro ${ }^{4}$, Jose Fernando Rosalba ${ }^{4}$, Jorge Fiori Fernandes Sobreira ${ }^{4}$, Michel Michaelovitch de Mahiques ${ }^{5}$, Gilmar Vital Bueno ${ }^{6},{ }^{1}$ Observatório Nacional, ${ }^{2}$ Universidade Federal de Santa Catarina, ${ }^{3}$ Universidade Federal da Bahia, ${ }^{4}$ Petrobras, ${ }^{5}$ Universidade de São Paulo, ${ }^{6}$ Universidade Federal Fluminense.

Copyright 2021, SBGf - Sociedade Brasileira de Geofísica

This paper was prepared for presentation during the $17^{\text {th }}$ International Congress of the Brazilian Geophysical Society held in Rio de Janeiro, Brazil, 16-19 August 2021.

Contents of this paper were reviewed by the Technical Committee of the $17^{\text {th }}$ International Congress of the Brazilian Geophysical Society and do not necessarily represent any position of the SBGf, its officers or members. Electronic reproduction or storage of any part of this paper for commercial purposes without the written consent of the Brazilian Geophysical Society is prohibited.

\begin{abstract}
The coastal Southeastern region of Brazil concentrated most of Brazilian economical production and largest cities, as well as, nuclear power plants and the largest oil production fields. Despite having a low seismicity rate as compared with other intraplate areas, such as North America and Australia, the Brazilian continental margin lacks more studies for planning future offshore economic activities. This work describes the results from the first Ocean Bottom Seismometers (OBSs) deployed for long-term seismological studies in Brazilian territory carried out by a Brazilian researcher team. The OBS is an autonomous data-acquisition system that free falls to the seafloor to record seismic signals generated by earthquakes and other non seismic signals. Our results indicate that the OBSs provide useful data to retrieve signals that are not recorded by the land stations and they can significantly improve the seismic attributes retrieved in the offshore environment as well as to entice crust and lithospheric studies.
\end{abstract}

\section{Introduction}

The irregular distribution of seismic stations over the Earth's surface is a long-standing issue because around $71 \%$ of the Earth's surface is covered by water. Adding instrumentation to areas that are covered by oceans would considerably improve the seismological data density and provide details of Earth's interior structures, submarine faults, and deep-sea earthquakes (Webb, 1998). However, installing stations over the ocean floor has been a hard task due to technological and financial obstacles. As the ocean surface is a huge source of broadband seismic noise, long-term seafloor observations are necessary to better constrain local tectonics and seismic activity (Frontera et. al, 2010; Romanowicz et. al, 2009).

Deployment of a marine autonomous data-acquisition system (OBS) increased in the last decade (Dahm et al., 2006; Wilcock et al., 2013). Different multidisciplinary projects around the world have promoted campaigns for monitoring seismic signals generated by earthquakes and other underwater seismic sources. Despite the new technologies, working with OBS is still a blind deployment. Apart from very recently developed OBS systems, after the equipment free falls downwards to the seabed, the project team has typically severe strict communication with the OBS, so it is impossible to check whether the equipment is recording. At last, many of the critical problems with OBS are related to sensor - seabed coupling, noise level and battery charge durability. Ocean bottom seismometers traditionally record earthquakes and volcanic signals from the seafloor, however, there are numerous non seismic signals as well, mainly in the form of short-duration events (SDEs) in the vicinity of the equipment. Basti et al. (2019) describe the main SDEs characteristics: short duration (<1s), high-frequency content (between 4-30 Hz), high signal to noise ratio, and single impulsive wave train.

In order to improve the seismic monitoring of the southeast coast of Brazil, as a first step towards a marine branch of the Brazilian Seismographic Network (RSBR) (Bianchi et al., 2018), this work presents the installation of the first OBSs for long-term seismological studies in Brazilian territory by a Brazilian team, as part of a joint cooperation among Universidade Federal de Santa Catarina, Observatório Nacional and Petrobras. Six broadband OBSs were installed along the Brazilian continental margin in around oil fields (Figure 1). Our results evidenced a prolific growth of short-duration events registered in the vicinity of the OBSs locations.

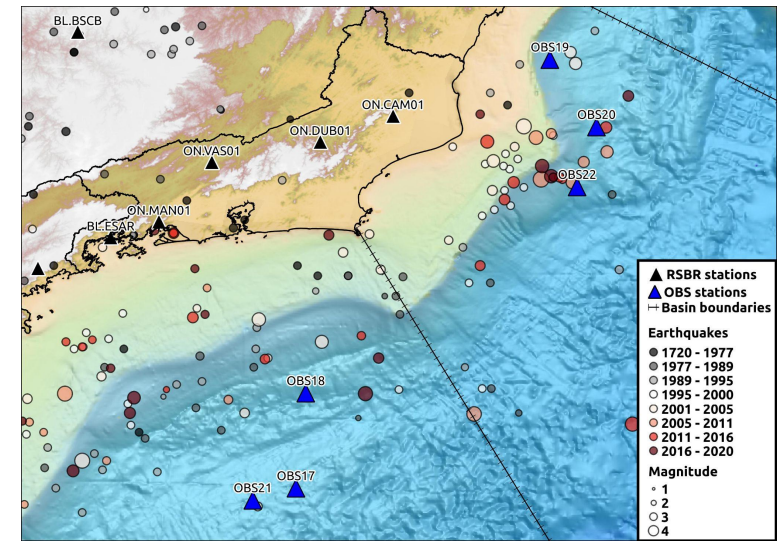

Figure 1 - Location of the six OBSs (blue triangles) and the earthquakes (circles) recorded by the RSBR stations (black triangles). Source: Altimetry (GEBCO, 2020), Bathymetry (LEPLAC, 2020), Shapefiles (CPRM, 2001). 


\section{New horizons in Brazilian Seismology}

\section{Method}

\section{Data acquisition}

The OBSs installed in the oil fields (Figure 1) are manufactured by Güralp, which consists of a high-density polythene cradle, cylindrical concrete ballasts and two glass spheres. One glass sphere containing the digitiser and the data storage unit, and another sphere, the release system. Each sphere has its own battery system, designed for lasting approximately one year. Furthermore, there is a central compartment, where the triaxial broadband seismometer (CMG-40T) is placed. Figure 2 shows the hydrophone attached to the OBS structure and the two cylindrical concrete weights at the base. The digitiser system acquires data from the vertical $(\mathrm{HHZ})$, horizontal (HHE and $\mathrm{HHN}$ ) and hydrophone (HHX) channels with a sampling rate of $100 \mathrm{~Hz}$.

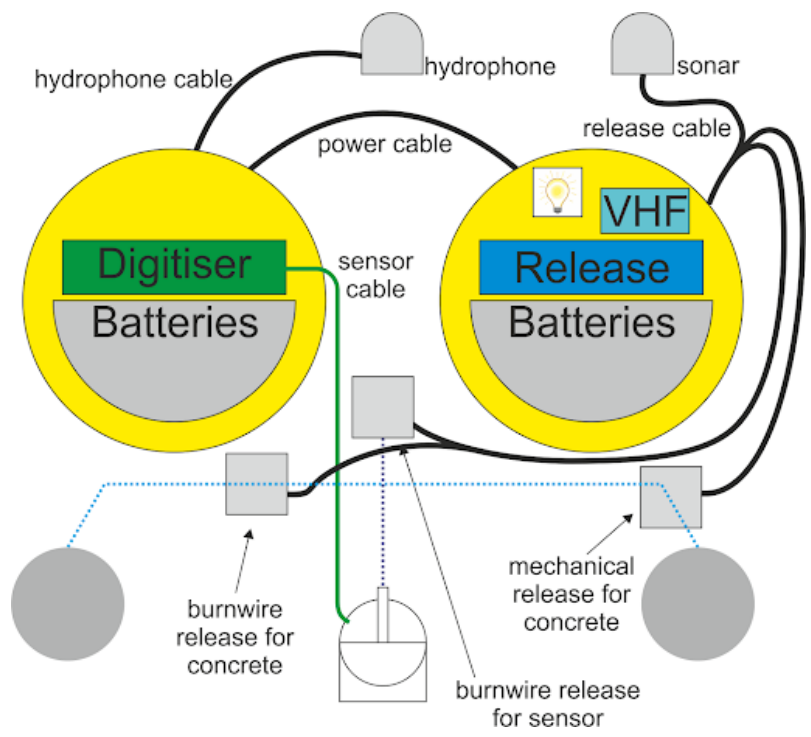

Figure 2 - Complete scheme of the OBS system (Source: Güralp Limited Systems, 2019).

The oceanographic cruise deployed the six OBSs in the offshore environment of the coastal basins in July 2019 and recovered the OBSs in June 2020. They were installed by free fall, where the equipment was lowered to the water surface and released to submerge downwards the seabed (Figure 3). The OBSs locations and their depths, after the deployment, were estimated by acoustic triangulation, where the equipment landed at most 0.5 NM (nautical miles) away from the location where they were launched. At recovery, the ship sends an acoustic command to the OBS to release the ballast, and then it returns to surface, as the structure of the OBS has positive buoyancy.

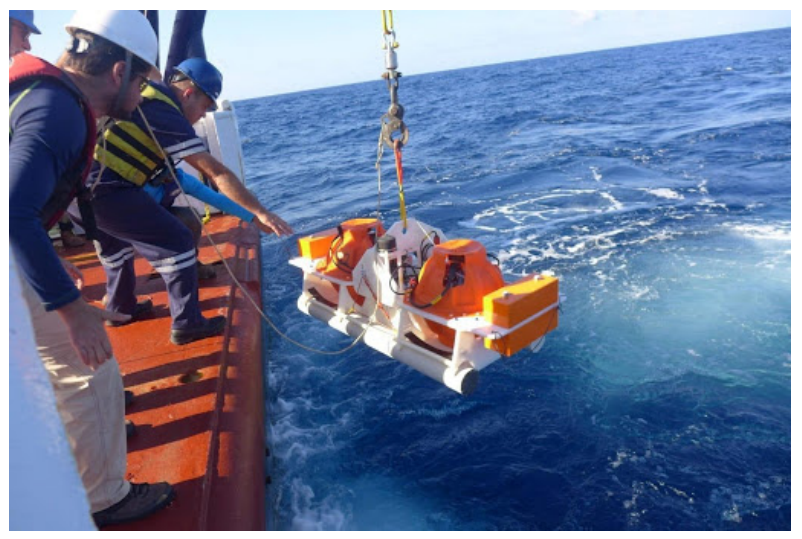

Figure 3 - The crew releasing OBS (CMG-40T Güralp). Photography: Luiz Antonio Pereira de Souza.

\section{Quality Control}

Summarising the quality control stage, only four OBSs (OBS17, OBS18, OBS19, OBS20) were recovered by the cruise and another one (OBS22) was found recently adrift on a beach in the south of Brazil without its sensor. From six OBSs, only two (OBS17 and OBS19) completed the entire expected cycle including installation, sensor seabed coupling and recovery. Effectively, just the OBS18 registered data between the installation and recovery; all the other OBSs presented problems with the battery system. The datalogger battery system did not present satisfactory performance, because in most of the OBSs, the datalogger stopped recording before the expected nominal battery lifetime ( one year), thus losing approximately $40 \%$ of the expected data set, as shown in Figure 4.

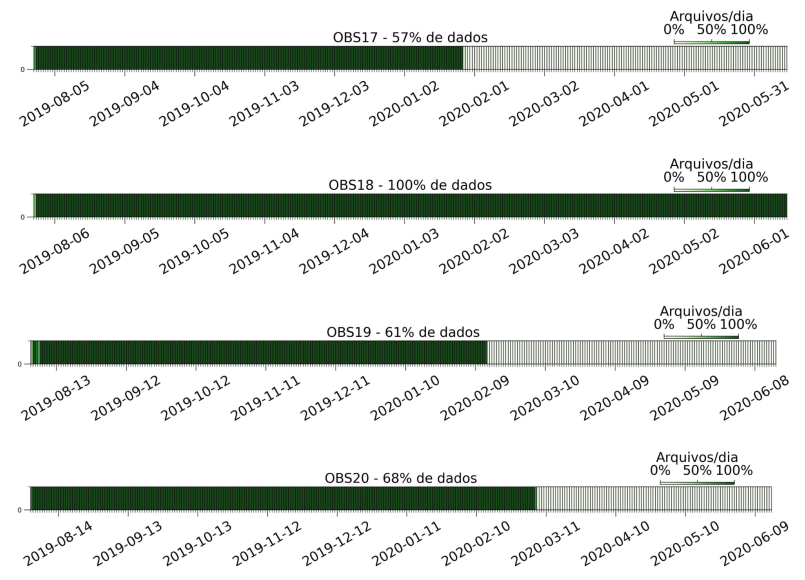

Figure 4 - Percentage of data according to the acquisition period for each OBS recovered. The OBS22 adrift recovered in a beach, was not yet processed.

Signal characterization contained in the acquired data is needed to draw the attainable goals. The first appraisal of both quality and performance of each OBS can be 
Oliveira-Coelho et al.

derived from the spectral information of the dataset (McNamara and Buland, 2004). Lower noise level is expected from the sensors that were properly coupled to the seabed, because they are less prone to ocean floor conditions (e.g., bottom currents). However, the OBS19, which has coupled, presents a high noise level (Figure 5, down left) and according to the masses' positions, the sensor was stuck at the seabed after landing on the ocean floor. The lack of coupling makes the HHN and HHE components noisier, especially in periods greater than 10 seconds. Despite the OBS18 and OBS20 not releasing the sensors, consequently, they are not coupled correctly on the ocean floor, their data may be partially used, mainly the data from vertical component and hydrophone.

\section{Corrections}

Typically, OBS data require the following corrections:

1) Time correction: crucial requirement to correct absolute timing of seismograms.

2) Tilt correction: for removing the tilt caused by seafloor currents flowing across the equipment.

3) Azimuthal correction: to determine the unknown horizontal orientation of the sensors due to free-fall deployment.

4) Compliance correction: to estimate and remove the effect of the pressure variations associated with infragravity waves in the data set.

Firstly, there is no communication with GPS at the ocean bottom, then the data time needs a clock time correction. Today, there are a few solutions to create a link of communication with the OBSs, such as nodes and wave gliders. However, these types of equipment are extremely expensive. Ocean tides and bottom currents can move the sensor at the seabed, so the tilt correction is a must for removing the effect of the tilt in the data set. Lastly, the sensor needs an azimuthal correction because it is not possible to align the sensor during the installation. For correcting the seafloor compliance, the OBS must have a differential pressure gauge (DPG) to measure the pressure variation at the ocean floor. The OBSs utilised in this project do not have such equipment, so the compliance correction was not done. The majority of these corrections use earthquakes records to correct the data set. However, the acquisition time of this project is restricted, so the cross-correlation of ambient noise was used to correct the data set. The clock drift was corrected using the methodology proposed by Hable et al. (2018) and the tilt correction followed the methodology of Bell et al. (2014). Both methodologies improve the signal to noise ratio from the vertical component, mainly below 1 $\mathrm{Hz}$. The azimuthal correction will follow the methodology proposed by Zha (2013), who retrieved the direction from Rayleigh wave polarization from ambient noise correlation.

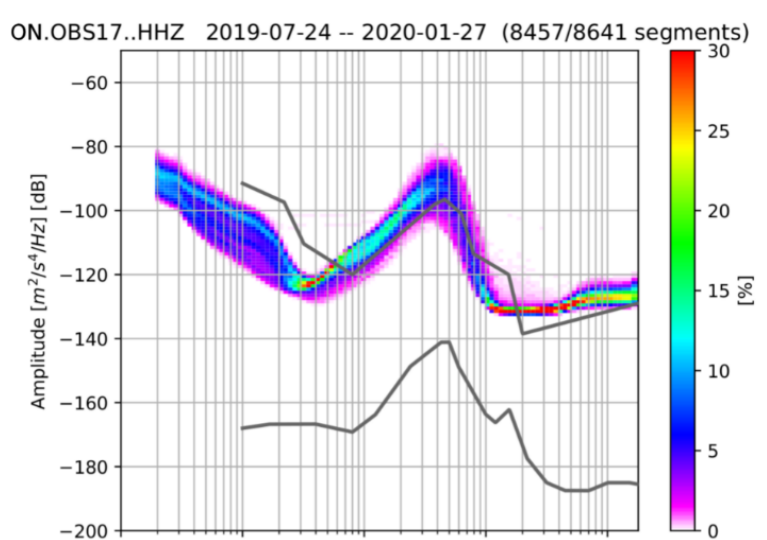

ON.OBS18..HHZ 2018-11-06 -- 2020-06-15 (14887/15212 segments)

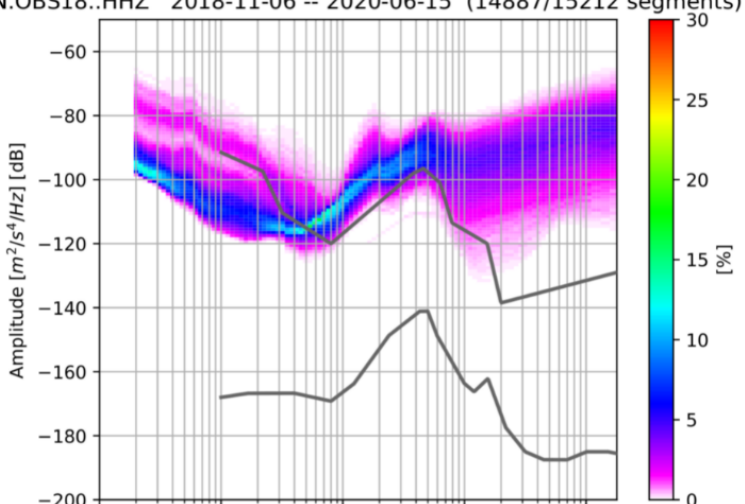

ON.OBS19..HHZ 2019-08-02 -- 2020-02-13 (8964/9158 segments)

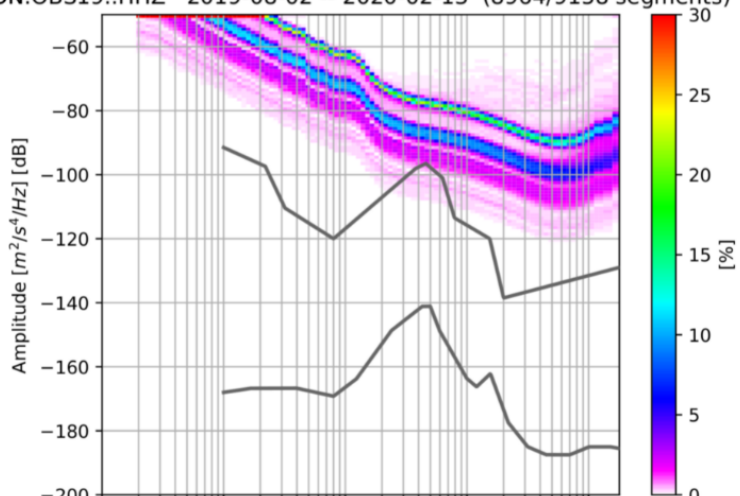

ON.OBS20..HHZ 2019-08-02 -- 2020-03-06 (10007/10224 segments)

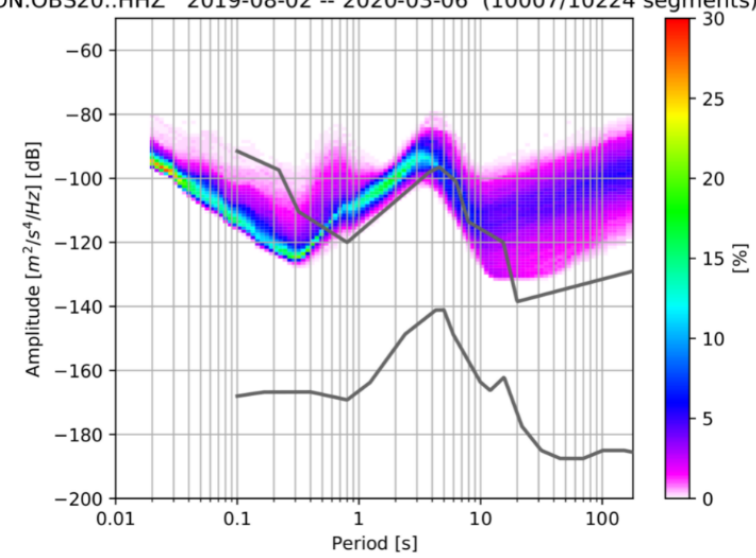

Figure 5 - Probability Density Functions for the vertical component of the 4 retrieved OBSs. 
New horizons in Brazilian Seismology

Local earthquakes detection

A single seismic station operating continuously produces an enormous amount of data, a seismic network produces even more data. Then, to analyze and locate seismic events becomes a laborious task for seismologists. Developing tools to deal with this hard task is crucial, the easiest way to contour this situation is the application of triggers, which are based on the amplitude, the envelope, or the power of the seismic signal in time or frequency domain. In this work, the methodology proposed by Trnkoczy (2012) was used to detect any amplitude that passed the pre-established threshold. The STA/LTA (short-time-average/long-time-average) method is usually used in weak-motion applications that try to record as many seismic events as possible. The algorithm continuously keeps track of changes in the amplitude; a successful capture of seismic events depends on the proper settings of the trigger parameters (Trnkoczy ,2012).

\section{Examples}

Figure 6 shows seismograms of the March 13, $2020 M_{w}$ 5.2 Northern Chile earthquake recorded by the RSBR stations (DUB01, CAM01, ABR01, RIB01 and GUA01) and the OBS18. The vertical-component data from these stations appear identical. However, the noise in the OBS and the station ABR01 (Abrolhos Archipelago) is much higher when compared with the stations located in the continent. The low signal to noise is related to the proximity of the ocean, the main noise source of the seismic data. Despite that, the data from these stations are usable and these stations are important to improve the azimuthal distribution of the seismic network over Brazilian territory.

Figure 7 shows a waveform example for a seismic event that occurs frequently on the Southeastern part of the Atlantic coast of Brazil. This event was recorded by the OBS17, OBS18, and ABR01 station. These type of seismic events are frequent in the OBS data set, and they are highly clustered, as shown in the Figure 8 . The majority of these clustered seismic events, or SDEs, found by the STA/LTA procedure are only registered by the OBSs, sometimes, the big ones, they are registered by other stations (Figure 8).

Figure 8 shows recordings of SDEs, which have several potential sources, such as micro-earthquakes, biological activities, and changes in the underlying soft sediments (Frontera et al., 2010). The occurrence of SDEs in long-lasting swarms is observed in Figure 8, which can be associated with pressure transients in the hydrothermal system and hydraulic fracturing. SDEs can also be associated with gas emissions out the seabed, if they occur during the same tidal phase and with comparable amplitudes (Basti et al., 2019). The data set is still in processing, and a more robust analysis demands more time.

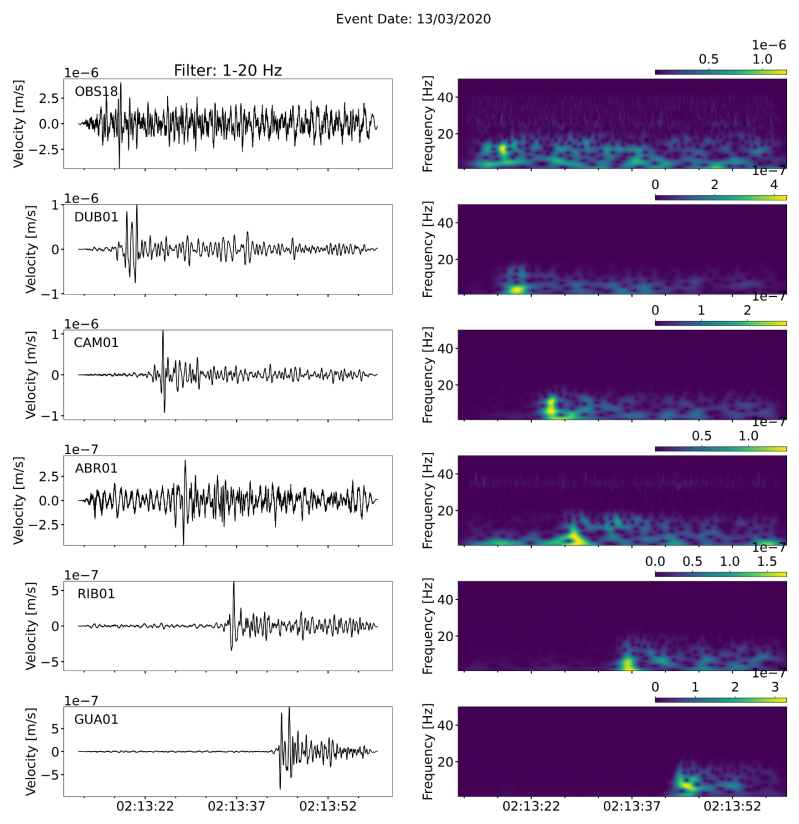

Figure 6 - Waveforms and spectrograms of vertical component at land, oceanic island, and ocean-bottom stations. The left and right panels present velocity waveforms and their spectrograms for the $5.2 M_{w}$ Chile earthquake. This event was registered by the RSBR at http://www.rsbr.gov.br/pevjs/event.html?usp2020fbsl.

\section{Conclusion}

The data set recorded by the OBSs during this project in the southeastern part of the Brazilian coast brings more experience and data for monitoring the seismicity of the continental margin, slope and deep sea. The noise level recorded by the OBSs is comparable with the noise of stations in oceanic islands. On the other hand, land stations have higher signal to noise than OBSs, as OBSs present low coupling with the seafloor. Our results indicate that OBS should provide good data, comparable to that achieved at island stations if the installation processes worked. Furthermore, these results showed how the addition of some OBSs can retrieve signals that are not recorded by the land stations and can significantly improve the seismologicalknowledge of the offshore area.

\section{Acknowledgments}

The authors gratefully acknowledge support from Petrobras through the 'Seismological and Oceanographic Monitoring of a Segment in Southeast Brazil: North of the Santos Basin to the South of the Espírito Santo Basin' project at Federal University of Santa Catarina (UFSC) and Observatório Nacional/MCTI, and the strategic importance of the support given by ANP through the R\&D levy regulation, process: 2015/00515-6. We thank the Brazilian Seismographic Network (www.rsbr.gov.br) for providing land seismological data. We thank the crew and 
Oliveira-Coelho et al.

researchers of R/V Alpha Crucis (USP) for their effective participation during the deployment cruises.
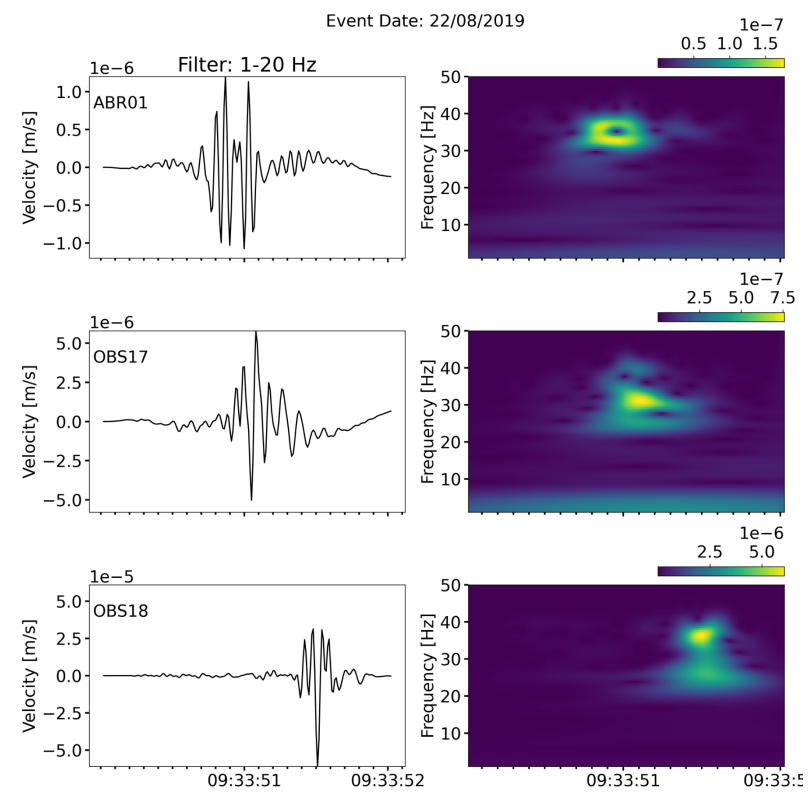

Figure 7 - The left and right panels present velocity waveforms and their spectrograms for a short-duration event (SDE) from the Atlantic Ocean.
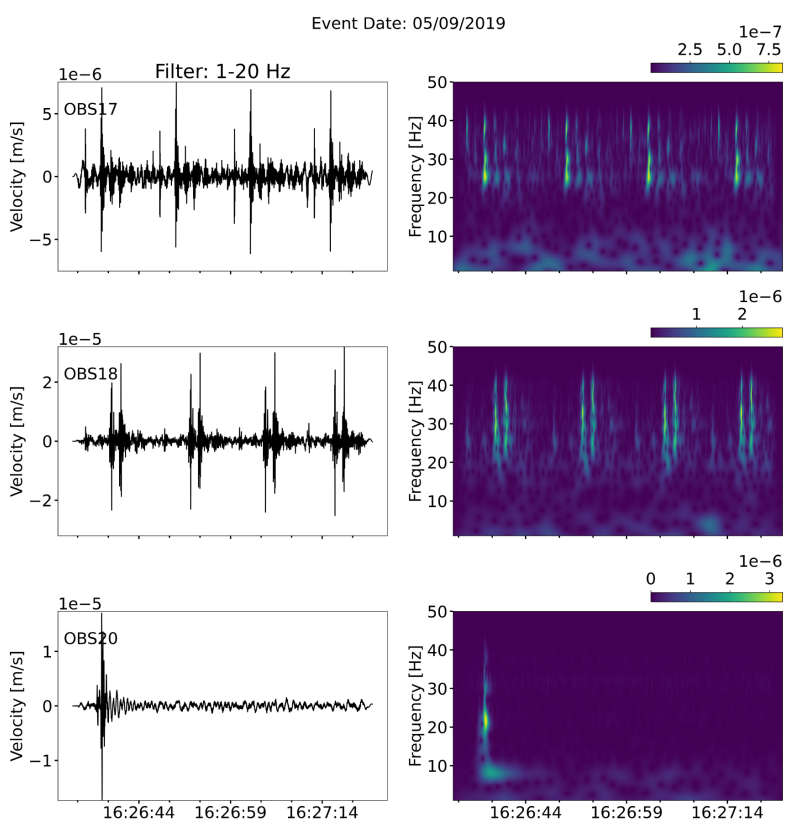

Figure 8 - The left and right panels present velocity waveforms and their spectrograms for a cluster of short-duration events near the OBS17 and OBS18.

\section{References}

BATSI, E.; et al. (2019). Nonseismic signals in the ocean: Indicators of deep sea and seafloor processes on ocean-bottom seismometer data. Geochemistry, Geophysics, Geosystems, 20, 3882-3900. https://doi.org/10.1029/2019GC008349.
BELL, S.W.; FORSYTH, D.W.; RUAN, Y. (2014) Removing noise from the vertical component records of ocean-bottom seismometers: results from year one of the Cascadia Initiative, Bulletin of the Seismological Society of America, 105, p. 300-313. doi: https://doi.org/10.1785/0120140054.

BIANCHI, M.B.; et al. (2018). The Brazilian Seismographic Network (RSBR): Improving Seismic Monitoring in Brazil. Seismological Research Letters; 89 (2A): 452-457. doi: https://doi.org/10.1785/0220170227.

CARTA BATIMÉTRICA GERAL DOS OCEANOS (General bathymetric chart of the oceans) GEBCO (2020). Disponível em: https://www.gebco.net/. Acesso em 31 de Agosto de 2020.

CPRM (2001). Geologia, Tectônica e Recursos minerais do Brasil: Sistema de informações geográficas - SIG e mapas na escala 1:2.500.000. in: Bizzi, L.A.; Schobbenhaus, C.; Gonçalves, J.H.; Baars, F.J.; Delgado, I.M., Abram, M.B., Leão Neto, R., Matos, G.M.M., Santos, J.O.S. Brasília: CPRM, 2001. 4 CD-ROM.

DAHM, T.; TILMANN, F.; MORGAN, J.P. (2006). Seismic Broadband Ocean-Bottom Data and Noise Observed with Free-Fall Stations: Experiences from Long-Term Deployments in the North Atlantic and the Tyrrhenian Sea. Bulletin of the Seismological Society of America; 96 (2): 647-664. doi: https://doi.org/10.1785/0120040064.

FRONTERA, T.; UGALDE, A.; OLIVERA, C.; JARA, J.A.; GOULA, X. (2010). Seismic Ambient Noise Characterization of a New Permanent Broadband Ocean Bottom Seismometer Site offshore Catalonia (Northeastern Iberian Peninsula). Seismological Research Letters.; 81 (5): 740-749. doi: https://doi.org/10.1785/gssrl.81.5.740.

GÜRALP LIMITED SYSTEMS. (2019). Portable Ocean Bottom Seismometer System - Technical Manual.

HABLE, S.; SIGLOCH, K.; BARRUOL, G.; STÄHLER, S.C.; HADZIIOANNOU, C. (2018). Clock Errors in land and ocean bottom seismograms: high-accuracy estimates from multiple-component noise cross-correlations. Geophysical Journal International, V. 214, P. 2014-2034.

MCNAMARA, D.E.; BULAND, R. (2004). Ambient Noise Levels in the Continental United States. Bulletin of the Seismological Society of America; v.94; n.4; p. 1517-1527.

PLANO DE LEVANTAMENTO DA PLATAFORMA CONTINENTAL BRASILEIRA - LEPLAC (2020). Disponível: https://www.marinha.mil.br/secirm/leplac. Acesso em: 26 de Agosto de 2020.

ROMANOWICZ, B.; MCGILL, P.; NEUHAUSER, D.; DOLENC, D. (2009). Acquiring Real Time Data from the Broadband Ocean Bottom Seismic Observatory at 
New horizons in Brazilian Seismology

Monterey Bay (MOBB). Seismological Research Letters, 80(2), 197-202. doi:10.1785/gssrl.80.2.197.

TRNKOCZY, A. (2012) Understanding and Parameter Setting of STA/LTA trigger algorithm. - In: Bormann, P. (Ed.), New Manual of Seismological Observatory Practice. Deutsches Geoforschungszentrum Gfz, 1-20. doi: https://Doi.Org/0.2312/Gfz.Nmsop-2_is_8.1.

WEBB, S. C. (1998). Broadband seismology and noise under the ocean. Reviews of Geophysics, 36(1), 105-142. doi:10.1029/97rg02287.

WILCOCK, W.S.D.; STAFFORD, K.M.; ANDREW, R.K.; ODOM, R.I. (2014). Sounds in the Ocean at $1-100 \mathrm{~Hz}$. Annual Review of Marine Science 6:1, 117-140.

ZHA, Y.; WEBB, S. C.; MENKE, W. (2013). Determining the orientations of ocean bottom seismometers using ambient noise correlation, Geophys. Res. Lett., 40, 3585-3590 doi:10.1002/grl.50698. 